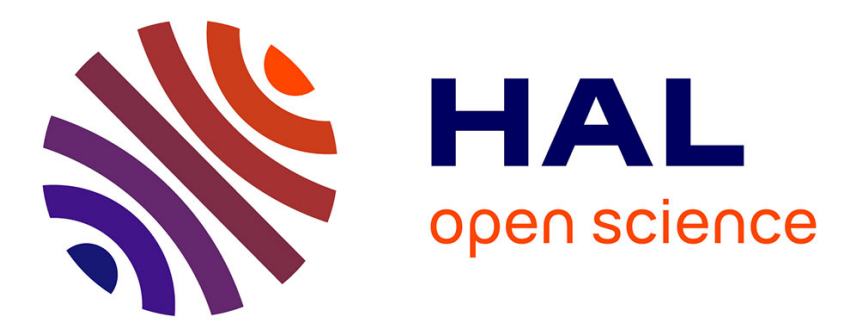

\title{
Chorus and chorus-like emissions seen by the ionospheric satellite DEMETER
}

Michel Parrot, Ondřej Santolík, František Nĕmec

\section{To cite this version:}

Michel Parrot, Ondřej Santolík, František Němec. Chorus and chorus-like emissions seen by the ionospheric satellite DEMETER. Journal of Geophysical Research Space Physics, 2016, 121 (4), pp.37813792. 10.1002/2015JA022286 . insu-01372224

\section{HAL Id: insu-01372224 \\ https://hal-insu.archives-ouvertes.fr/insu-01372224}

Submitted on 1 Dec 2016

HAL is a multi-disciplinary open access archive for the deposit and dissemination of scientific research documents, whether they are published or not. The documents may come from teaching and research institutions in France or abroad, or from public or private research centers.
L'archive ouverte pluridisciplinaire $\mathbf{H A L}$, est destinée au dépôt et à la diffusion de documents scientifiques de niveau recherche, publiés ou non, émanant des établissements d'enseignement et de recherche français ou étrangers, des laboratoires publics ou privés. 


\section{Journal of Geophysical Research: Space Physics}

\author{
RESEARCH ARTICLE \\ 10.1002/2015JA022286 \\ Key Points: \\ - Chorus and chorus-like elements \\ observed by DEMETER \\ - Intensity of downgoing chorus is \\ reinforced close to the trough \\ - Some chorus-like elements attributed \\ to emissions triggered by PLHR
}

Correspondence to:

M. Parrot,

mparrot@cnrs-orleans.fr

\section{Citation:}

Parrot, M., O. Santolík, and F. Nĕmec (2016), Chorus and chorus-like emissions seen by the ionospheric satellite DEMETER, J. Geophys. Res. Space Physics, 121, 3781-3792, doi:10.1002/ 2015JA022286.

Received 18 DEC 2015 Accepted 29 MAR 2016 Accepted article online 5 APR 2016 Published online 30 APR 2016

\section{Chorus and chorus-like emissions seen by the ionospheric satellite DEMETER}

\author{
Michel Parrot ${ }^{1}$, Ondřej Santolík ${ }^{2,3}$, and František Nĕmec ${ }^{2}$ \\ ${ }^{1}$ LPC2E/CNRS, Orléans, France, ${ }^{2}$ Faculty of Mathematics and Physics, Charles University in Prague, Prague, Czech Republic, \\ ${ }^{3}$ Institute of Atmospheric Physics, Czech Academy of Sciences, Prague, Czech Republic
}

\section{Introduction}

The aim of this study is to analyze the variety of chorus and chorus-like emissions observed by the ionospheric satellite DEMETER (Detection of Electro-Magnetic Emissions Transmitted from Earthquake Regions). Chorus emissions are intense whistler-mode waves consisting of a series of rising or falling tones in frequency and separated by a few tenths of seconds (see reviews by Kulkarni and Das [1992], Sazhin and Hayakawa [1992], Santolik [2008], and Tsurutani et al. [2013], and references therein). Most of the time, they are observed between 2300 and 1300 MLT in the dawnside [Tsurutani and Smith, 1974]. Generally, they are divided into lower and upper bands of elements centered at half the equatorial cyclotron frequency $f_{\text {ce }}$ on the magnetic field line of the satellite observing these emissions [Tsurutani and Smith, 1974; Burtis and Helliwell, 1976]. They are due to a nonlinear generation mechanism involving wave-particle interaction with energetic electrons, and then, they can play a significant role in the dynamics of the radiation belts [Omura and Nunn, 2011]. One can also see works related to rising and falling tone structures by Summers et al. [2014] and Omura et al. [2015]. The chorus source is near the magnetic equatorial plane at distances from $\sim 3$ to 10 Earth radii [LeDocq et al., 1998; Parrot et al., 2003; Santolik et al., 2005]. Using a ray-tracing code, Chum and Santolik [2005] have demonstrated that chorus propagating from this source close to the equatorial plane can reach the topside ionosphere. This was later confirmed by Bortnik et al. [2007] who underlined that it can lead to generation of other emissions (e.g., extremely low frequency (ELF) hiss) as it was proposed by Parrot et al. [2004a, 2004b], Chum and Santolik [2005], and Santolik et al. [2006]. For example, Santolik et al. [2006] demonstrated that the ELF hiss commonly observed in the dayside is only a low-altitude indicator of natural magnetospheric whistler-mode chorus waves.

Some chorus emissions observed by DEMETER have already been studied. On the one hand, Manninen et al. [2012] have shown for the first time that ground-based observations of premidnight chorus were coinciding with chorus waves registered in the late morning by DEMETER (same geomagnetic latitudes but opposite local time). As these chorus bursts were registered in a global longitudinal scale, they suggested that they were simultaneously generated at different longitudes. On the other hand, chorus observations at Marion Island have been correlated with DEMETER data by Delport et al. [2012] to determine temporal and spatial variations in the region of the chorus source. 


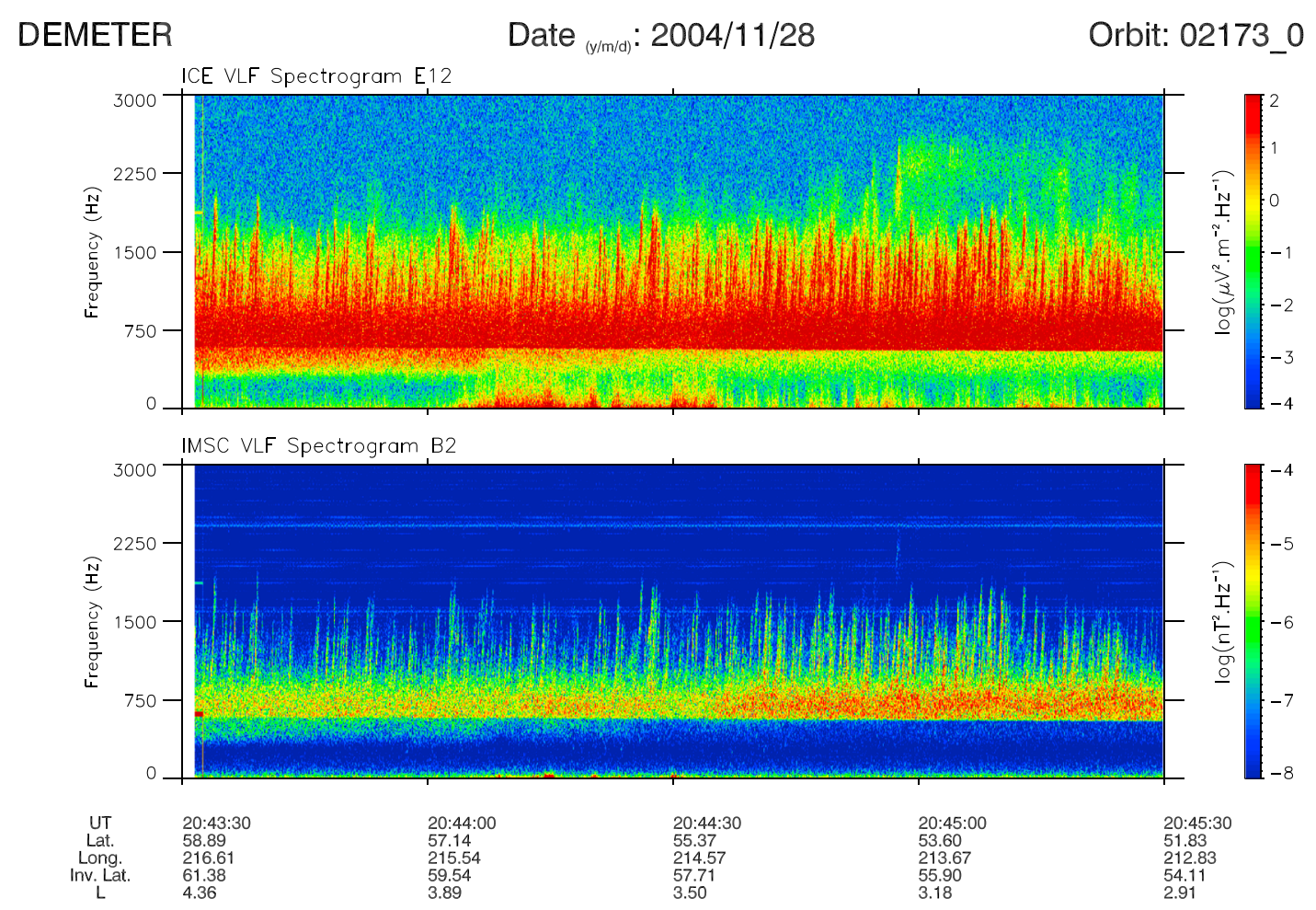

Figure 1. Spectrograms up to $3 \mathrm{kHz}$ of (top) an electric component and (bottom) a magnetic component registered on 28 November 2004 between 20:43:30 and 20:45:30 UT. The intensity of the spectrograms is color coded in accordance with the scales on the right. The frequency resolution is $9.7 \mathrm{~Hz}$, whereas the time resolution is $0.1 \mathrm{~s}$. The orbital parameters presented below are the time in UT, the geographic latitude and longitude, the invariant latitude, and the Mcllwain parameter $L$.

On ground or on board low-altitude satellites it is sometimes difficult to confirm that the observed elements drifting in frequency with time really correspond to whistler-mode chorus. The emissions observed by DEMETER consist of single elements, elements emerging from a hiss band, series of hooks starting at a constant frequency, and elements linked to quasiperiodic (QP) emissions. All occur at various frequencies, and very often two different bands of elements are present. Earlier, Luette et al. [1977] have shown that some chorus waves rather appear at longitudes of industrial areas located at high latitudes. They said that power line harmonic radiation (PLHR) can trigger chorus emissions through cyclotron resonance mechanism with trapped energetic electrons. It was confirmed by Park et al. [1981] who investigated the very low frequency (VLF) waves recorded at Siple, Antarctica $(L \sim 4)$. They have observed two distinct categories of chorus: (i) one correlated to electron fluxes with a generation region outside the plasmapause and (ii) a second inside the plasmapause which appears to be produced by whistlers, PLHR, and other signals. A review by Omura et al. [1991] presents the triggering mechanism of such waves. Concerning the PLHR, one can also see Nunn et al. [1999].

The aim of this paper is to show and to analyze, when it is possible, the various chorus and chorus-like emissions recorded by the ionospheric satellite DEMETER. The description of its onboard electric field and magnetic field experiments can be found in Berthelier et al. [2006] and Parrot et al. [2006], respectively. A variety of events is described in section 2, and to characterize the emissions, a wave propagation analysis has been done with methods for multicomponent measurements developed by Santolik et al. [2006]. Relations with PLHR are discussed in section 3. Conclusions are given in section 4.

\section{Observations}

\subsection{Typical Chorus Emissions}

Figure 1 presents an example of classical chorus electric and magnetic spectrograms observed by DEMETER during 2 min between 20:43:30 and 20:45:30 UT on 28 November 2004. During this time interval, the $L$ range extends from 4.36 to 2.91 . These emissions are recorded on the dayside during the recovery phase of a weak 
DEMETER 2004-11-28 20:43:31.712 - 2004-11-28 20:45:29.370

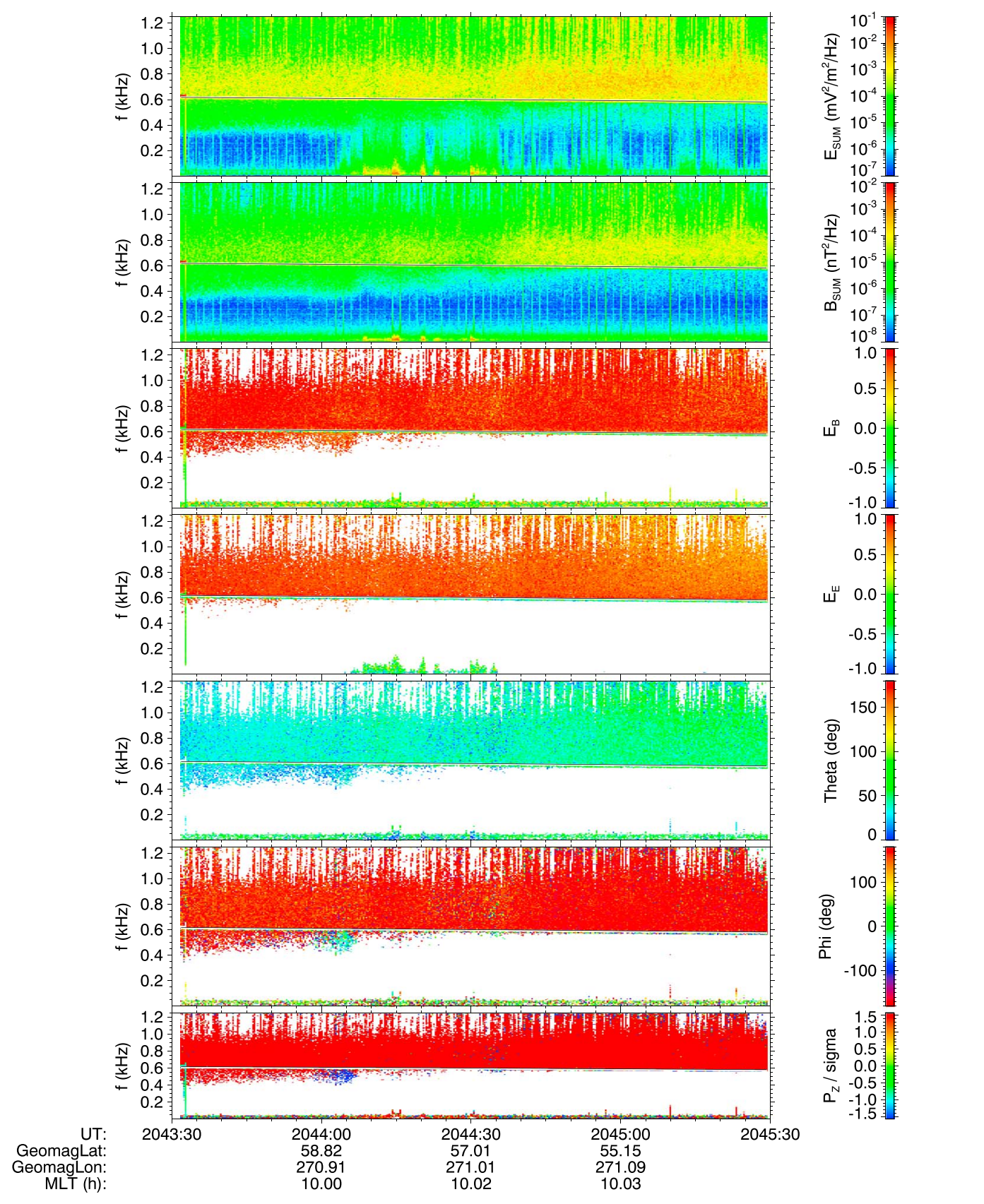

Figure 2. Wave propagation analysis of the data presented in Figure 1. (first panel) The sum of the three electric spectra, (second panel) the sum of the three magnetic spectra, (third panel) the ellipticity $E_{B}$ using the magnetic component and (fourth panel) the ellipticity $E_{E}$ using the electric component, (fifth and sixth panels) the wave normal angles $\theta$ and $\phi$, and (seventh panel) the direction of the Poynting vector (see text for explanation). In each panel the proton gyrofrequency which is around $600 \mathrm{~Hz}$ is indicated by a black line. The universal time (UT), the geomagnetic latitude and longitude, and the magnetic local time (MLT) are indicated below.

magnetic storm. The minimum value of the Dst index is equal to $-50 \mathrm{nT}$ at 07:00:00 UT and $-17 \mathrm{nT}$ at the time of the record. It is shown that the chorus elements with frequencies up to $2 \mathrm{kHz}$ are emerging from a hiss band with an upper limit of $930 \mathrm{~Hz}$ and a lower limit close to the proton gyrofrequency $(580 \mathrm{~Hz})$. The propagation characteristics of emissions seen at frequencies lower than $1.25 \mathrm{kHz}$ can be determined when the acquisition system is in burst mode [Santolik et al., 2006]. Figure 2 shows the propagation analysis of 
the emissions shown in Figure 1. Figure 2 (first and second panels) present spectrograms of the magnetic and electric field. Figure 2 (third panel) represents the ellipticity $E_{B}$ (ratio of the axes of the magnetic field polarization) obtained with a singular value decomposition (SVD) method [Santolik et al., 2002], while the sign of $E_{B}$ gives the sense of polarization relative to the stationary magnetic field: negative values correspond to left-handed polarization sense, whereas positive values correspond to right-handed polarization sense. Figure 2 (fourth panel) shows the ellipticity $E_{E}$ obtained with the electric components. Figure 2 (fifth panel) displays the wave normal angle $\theta$ which is the angle between the Earth's magnetic field and the wave vector, evaluated by the electromagnetic SVD method [Santolik et al., 2003]. Figure 2 (sixth panel) displays the corresponding azimuthal angle $\phi$. Figure 2 (seventh panel) presents the Poynting vector component along the Earth's magnetic field normalized by its standard deviation due to the statistical errors of the spectral analysis [Santolik et al., 2001]. The white areas in the panels are related to spectrograms where the magnetic power spectral densities are less than $10^{-7} \mathrm{nT}^{2} \mathrm{~Hz}^{-1}$ or the electric power spectral densities are less than $10^{-6} \mathrm{mV}^{2} \mathrm{~m}^{-2} \mathrm{~Hz}^{-1}$. These areas are empty because the analysis is not significant for waves with low intensity.

This analysis of plasma waves as a function of the time and the frequency indicates that the emissions are quasi field-aligned (low $\theta$ values of the order of $20^{\circ}$ ) and right-handed circularly polarized $\left(E_{B}\right.$ is close to +1$)$. Regarding the propagation, the analysis in Figure 2 (seventh panel) shows that the elements are propagating in the direction of the terrestrial magnetic field. Considering that the event occurs in the Northern Hemisphere, it signifies that the chorus elements are going downward as it is expected for waves generated at the magnetic equator. One also notices that the $\theta$ values increase when the magnetic latitude decreases.

\subsection{Mix of Chorus and Chorus-Like Emissions}

An electric spectrogram up to $4 \mathrm{kHz}$ recorded on 16 February 2007 during $1 \mathrm{~min}$ between 21:54:00 and 21:55:00 UT is displayed in Figure 3 (top). There are apparently two bands. The lower band from $260 \mathrm{~Hz}$ up to $1300 \mathrm{~Hz}$ looks like classical chorus elements emerging from hiss, but the upper band centered around $2 \mathrm{kHz}$ mainly consists of hooks. It means that although it looks like typical chorus emissions with two bands, the detailed spectrogram indicates that the upper band is not composed of classical chorus elements but of triggered elements. Another example is given in Figure 3 (bottom) which displays a spectrogram up to $5 \mathrm{kHz}$ of an electric component registered on 29 March 2007 between 05:46:30 and 05:48:30 UT. One can see two chorus bands: (i) a first band with chorus elements up to $980 \mathrm{~Hz}$ emerging from a hiss band as it is in Figures 1 and 3 (top) and (ii) a second band centered around $1400 \mathrm{~Hz}$ with additional triggered elements up to $2300 \mathrm{~Hz}$.

The propagation analysis has been done for the events of Figure 3 (top), and it is shown in Figure 4 with panels similar to Figure 2. Three points must be underlined. The first is that the lower band of the event is in fact composed of two distinct chorus bands which are separated by the proton gyrofrequency which is around $620 \mathrm{~Hz}$. But Figure 4 (fifth and seventh panels) indicate that their propagation characteristics are similar: waves with a small angle $\theta$ and propagating from above. The second point is that close to the proton gyrofrequency $(\sim 620 \mathrm{~Hz})$ there is a cutoff at the multi-ion cutoff frequency which leads to a change of the wave propagation characteristics in a very small frequency band around $620 \mathrm{~Hz}$ (see Santolik and Parrot [1999] for explanation). This is also true for the parameters shown in Figure 2 but not so visible. The third point is that we clearly see in Figure 4 (first panel) that the frequency of the chorus elements extends well below the proton gyrofrequency. This transmission was first explained by Gurnett and Burns [1968] by mode coupling near the crossover frequency. This tunneling effect occurs only for low wave normal angles, which is consistent with the values observed in Figure 4 (fifth panel).

Figure 5 displays data recorded on 8 May 2008 along the same orbit in the two hemispheres. Figure 5 (top) shows a spectrogram up to $5 \mathrm{kHz}$ of an electric component recorded during 2 min between 21:23:30 and 21:25:30 UT in the Northern Hemisphere ( $L$ range from 6.59 to 3.88). Figure 5 (bottom) shows the same spectrogram recorded during 2 min between 21:56:00 and 21:58:00 UT but in the Southern Hemisphere at the same $L$ values ( $L$ range from 3.82 to 6.37). These data are recorded during a very low magnetic activity with Dst values larger than $-10 \mathrm{nT}$. It is remarkable that we have symmetry in the two hemispheres half an hour later; i.e., similar patterns are observed at the same $L$ values in the north and the south:

1. There is a first chorus band mixed with hiss at low frequency below $1000 \mathrm{~Hz}$ as we have seen in the previous events. Waves observed below the proton gyrofrequency (around $590 \mathrm{~Hz}$ in Figure 5, top, and $680 \mathrm{~Hz}$ in Figure 5, bottom) have been investigated by Santolík and Parrot [1999]. 
DEMETER Date ${ }_{(\mathrm{y} / \mathrm{m} / \mathrm{d})}: 2007 / 02 / 16 \quad$ Orbit: $14020 \_0$

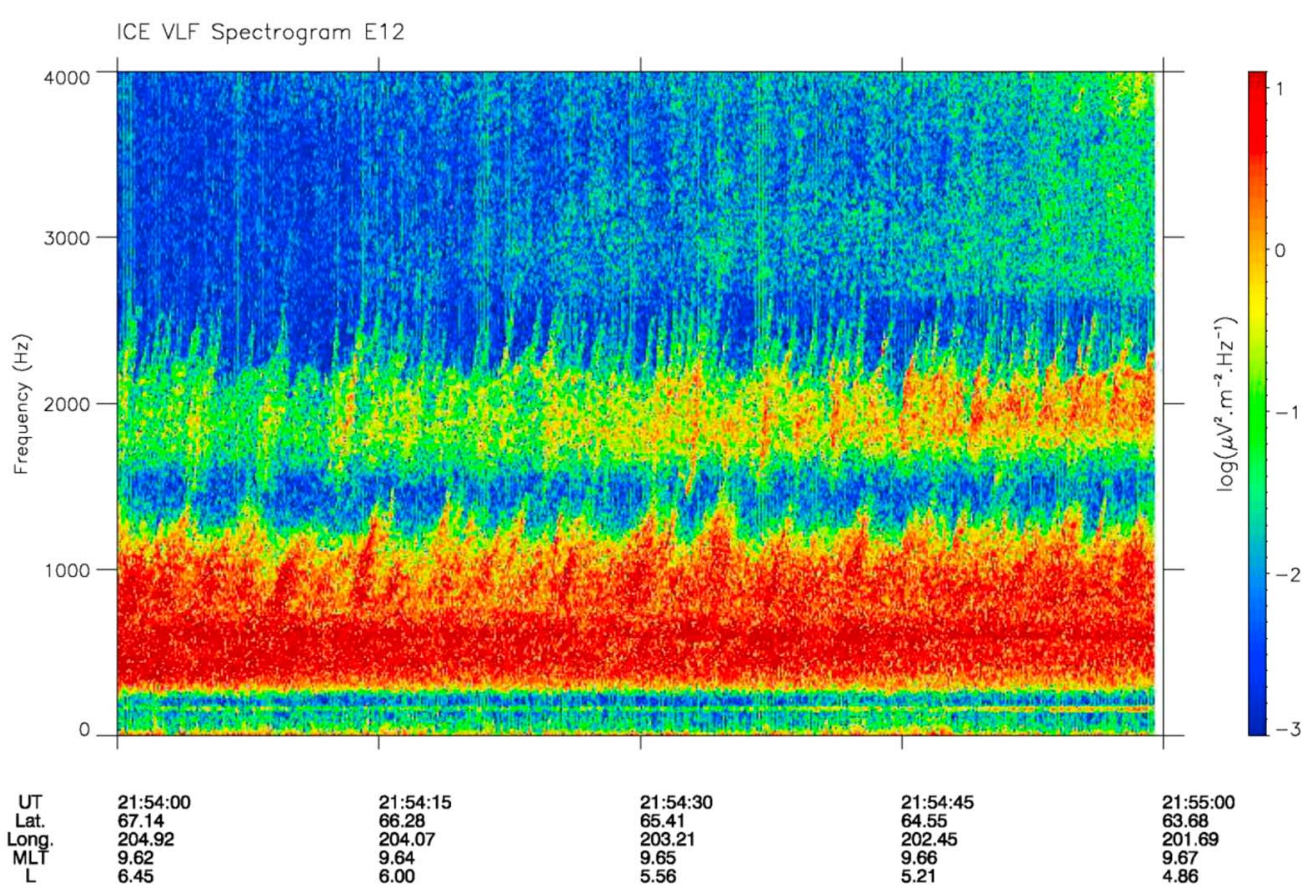

\section{DEMETER}

Date $_{(y / m /(s)}: 2007 / 03 / 29$

Orbit: 14612_0

ICE VLF Spectrogram E12

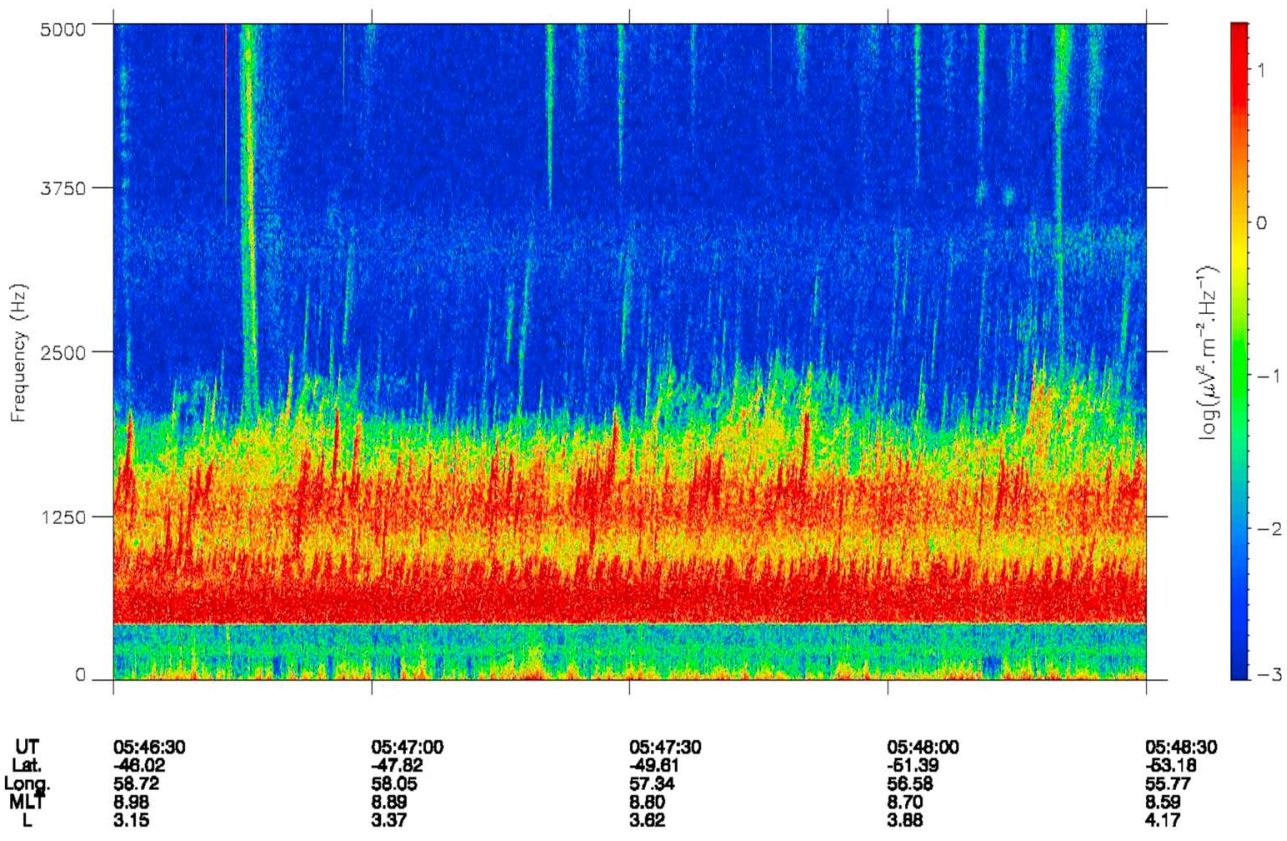

Figure 3. (top) Spectrogram up to $4 \mathrm{kHz}$ of an electric component registered on 16 February 2007 between 21:54:00 and 21:55:00 UT. (bottom) Spectrogram up to $5 \mathrm{kHz}$ of an electric component registered on 29 March 2007 between 05:46:30 and 05:48:30 UT. The intensities of the spectrograms are color coded in accordance with the scales on the right. The parameters presented below are the time in UT, the geographic latitude and longitude, the magnetic local time, and the Mcllwain parameter $L$. 


\section{DEMETER 2007-02-16 21:54:14.695 - 2007-02-16 21:54:59.240}

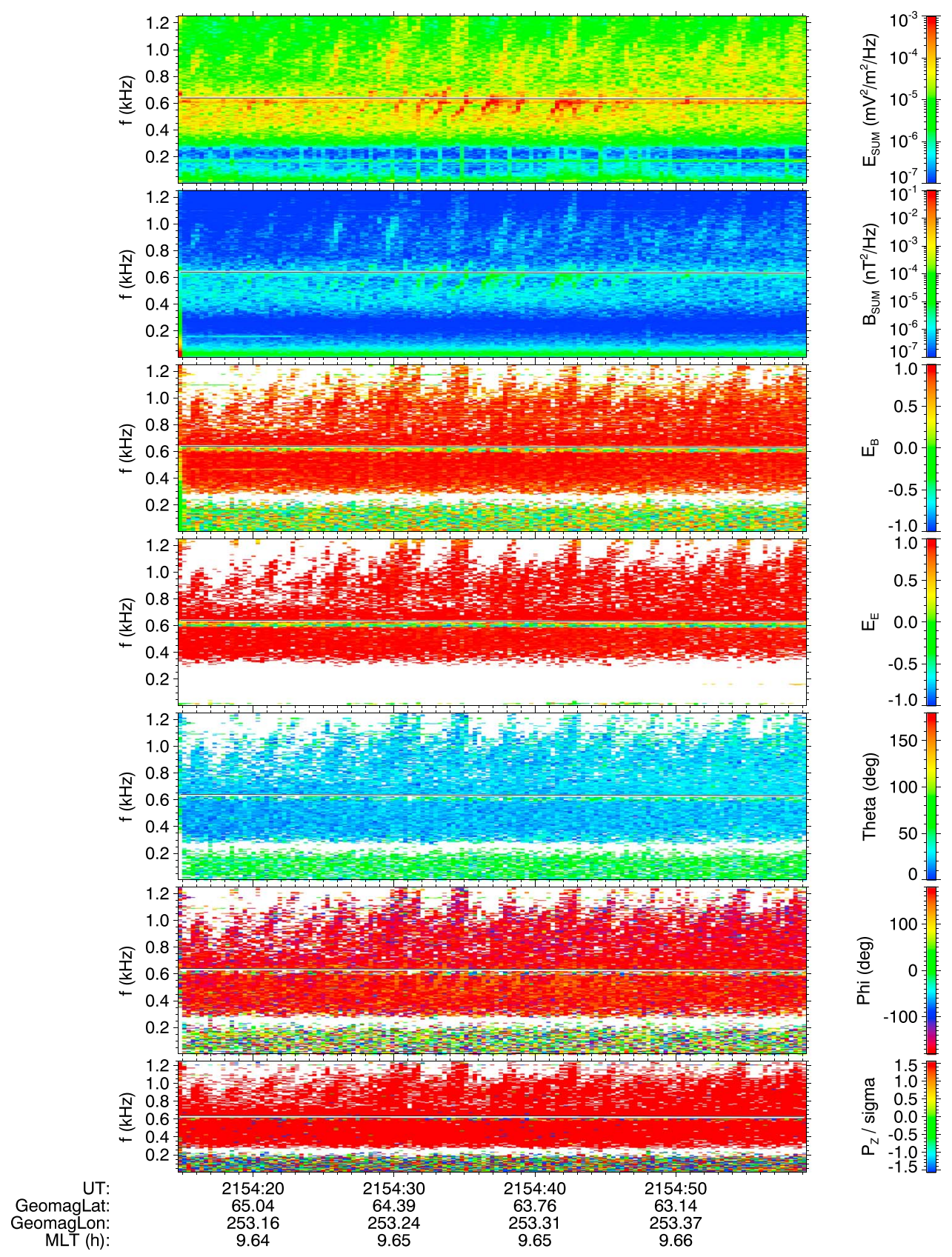

Figure 4. Wave propagation analysis of the data presented in Figure 3 (top) (except that the data for the first $14 \mathrm{~s}$ are missing because the magnetic field data contains interferences at the beginning of the burst mode). The parameters displayed in the panels are the same as in Figure 2 . In all these panels the proton gyrofrequency which is around $620 \mathrm{~Hz}$ is indicated by a black line.

2. Then there is a second band around $3750 \mathrm{~Hz}$ which seems independent with intensification above a narrow hiss band around $2500 \mathrm{~Hz}$ in the north (Figure 5, top) and $2800 \mathrm{~Hz}$ in the south (Figure 5, bottom).

3. On the side of the lower $L$ values $(L<4.8)$, this narrow hiss band ends with triggered elements made of falling tones and hooks which can be both possibly attributed to PLHR (see section 3 ).

4. The intensity of the elongated chorus elements around $3750 \mathrm{~Hz}$ are amplified at the time of observation of electrostatic (ES) turbulence (between 21:24:00 and 21:24:40 UT in the Northern Hemisphere and between 21:57:00 and 21:57:40 UT in the Southern Hemisphere) with low frequencies varying between 0 and 
DEMETER Date ${ }_{\text {y/m/(a) }}: 2008 / 05 / 08 \quad$ Orbit: 20585_0

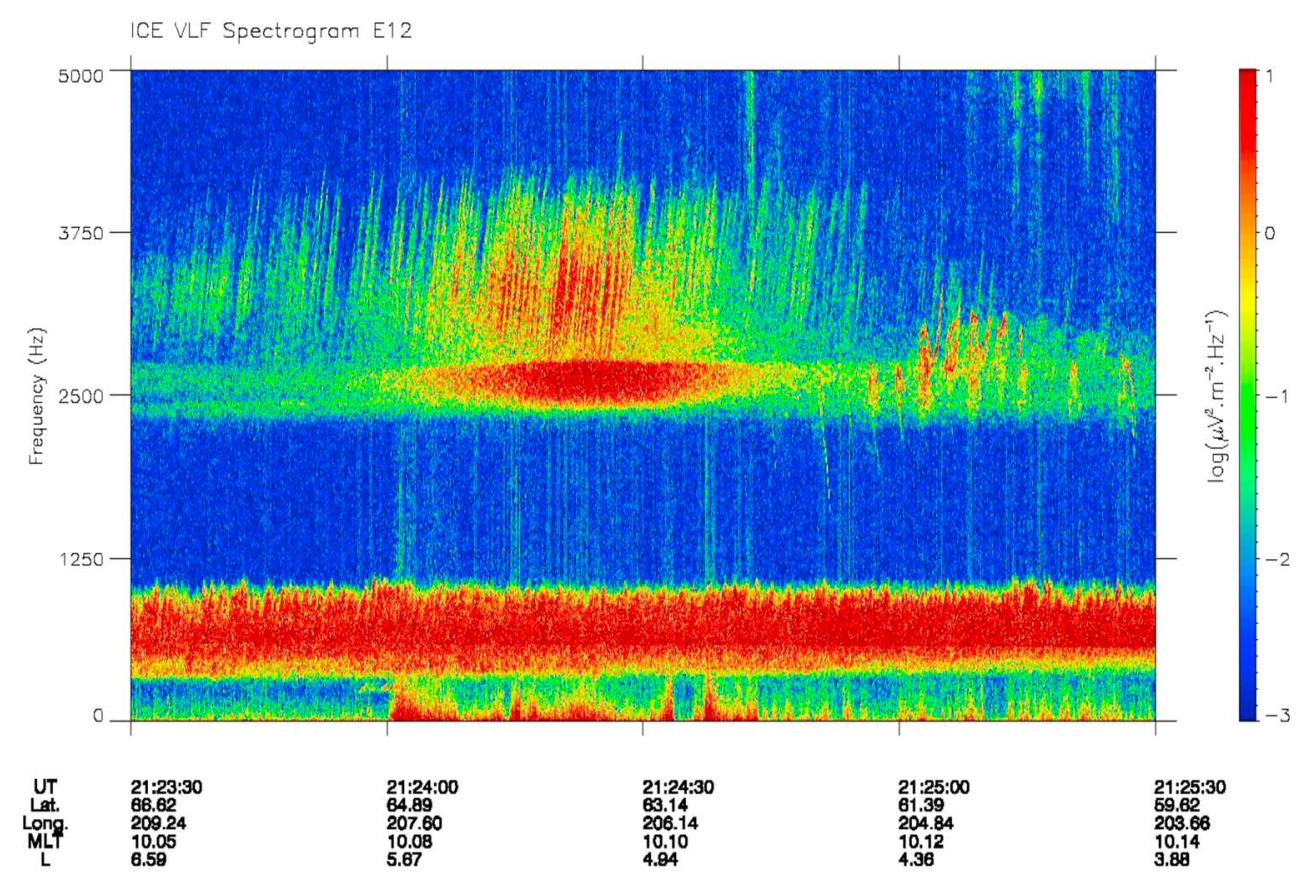

DEMETER Date ${ }_{(/ / m /())}: 2008 / 05 / 08 \quad$ Orbit: 20585_0

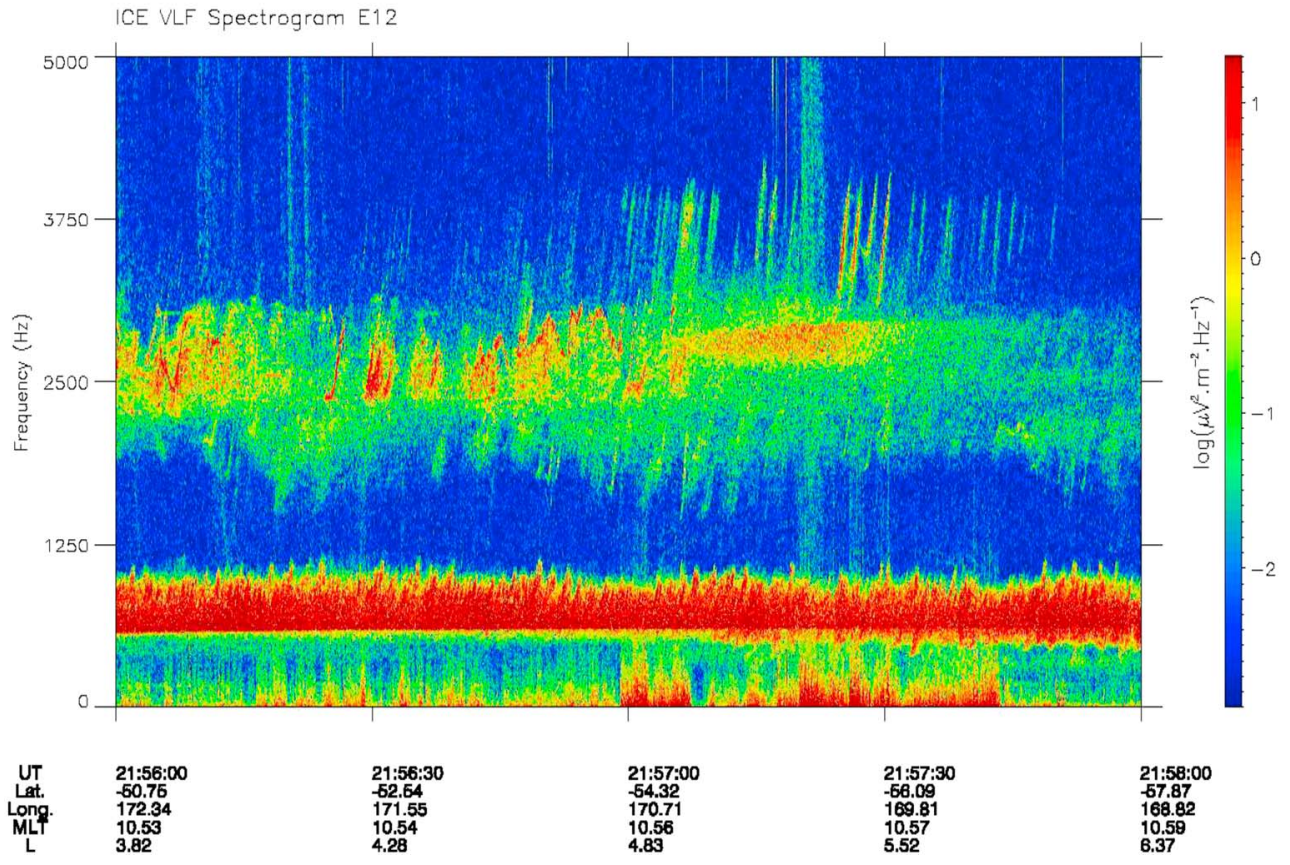

Figure 5. (top) Spectrogram up to $5 \mathrm{kHz}$ of an electric component registered on 8 May 2008 between 21:23:30 and 21:25:30 UT. (bottom) Spectrogram up to $5 \mathrm{kHz}$ of an electric component registered on the same day between 21:56:00 and 21:58:00 UT along the same orbit but in the opposite hemisphere at the same $L$ values. 


\section{DEMETER 2008-05-08 21:55:59.888 - 2008-05-08 21:58:00.003}

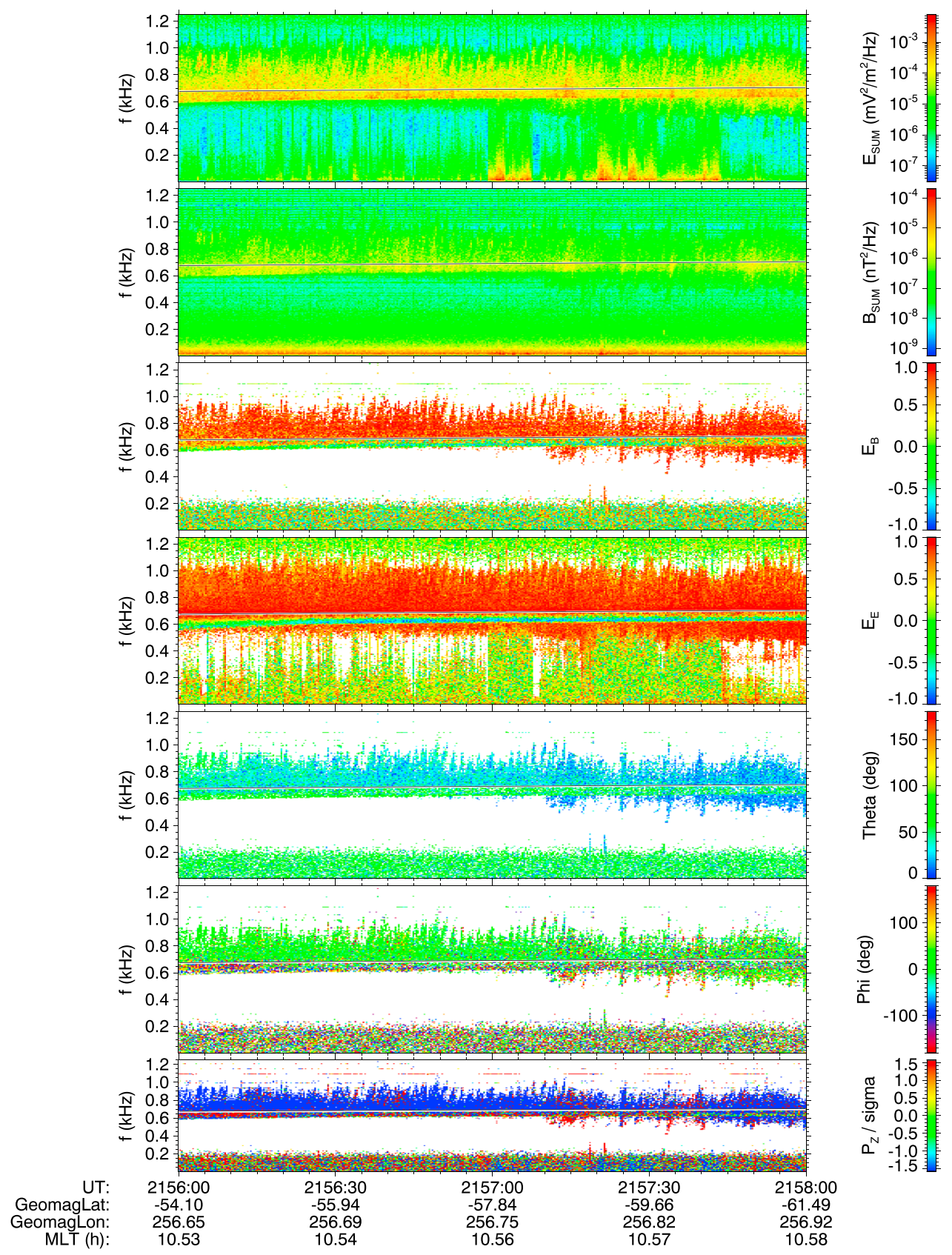

Figure 6. Wave propagation analysis of the data displayed in Figure 5 (bottom). The presentation is the same as in Figures 2 and 4. In each panel the proton gyrofrequency which is around $680 \mathrm{~Hz}$ is indicated by a black line.

$330 \mathrm{~Hz}$. This ES turbulence points out the location of the ionospheric trough which is known to be connected to the plasmapause at higher altitudes [Yizengaw et al., 2005]. It means that these chorus elements around $3750 \mathrm{~Hz}$ are propagating downward along the plasmapause.

5. The two hiss bands below these chorus elements (around $2500 \mathrm{~Hz}$ in Figure 5, top, and around $2800 \mathrm{~Hz}$ in Figure 5, bottom) are also amplified at the same location and could be due to the evolution of other chorus emissions propagating in the plasmasphere [see Chen et al., 2012].

Figure 6 corresponds to the propagation analysis of the chorus elements shown in Figure 5 (bottom) in the lower frequency band. Their propagation characteristics are similar to the ones shown in Figure 2. They are 

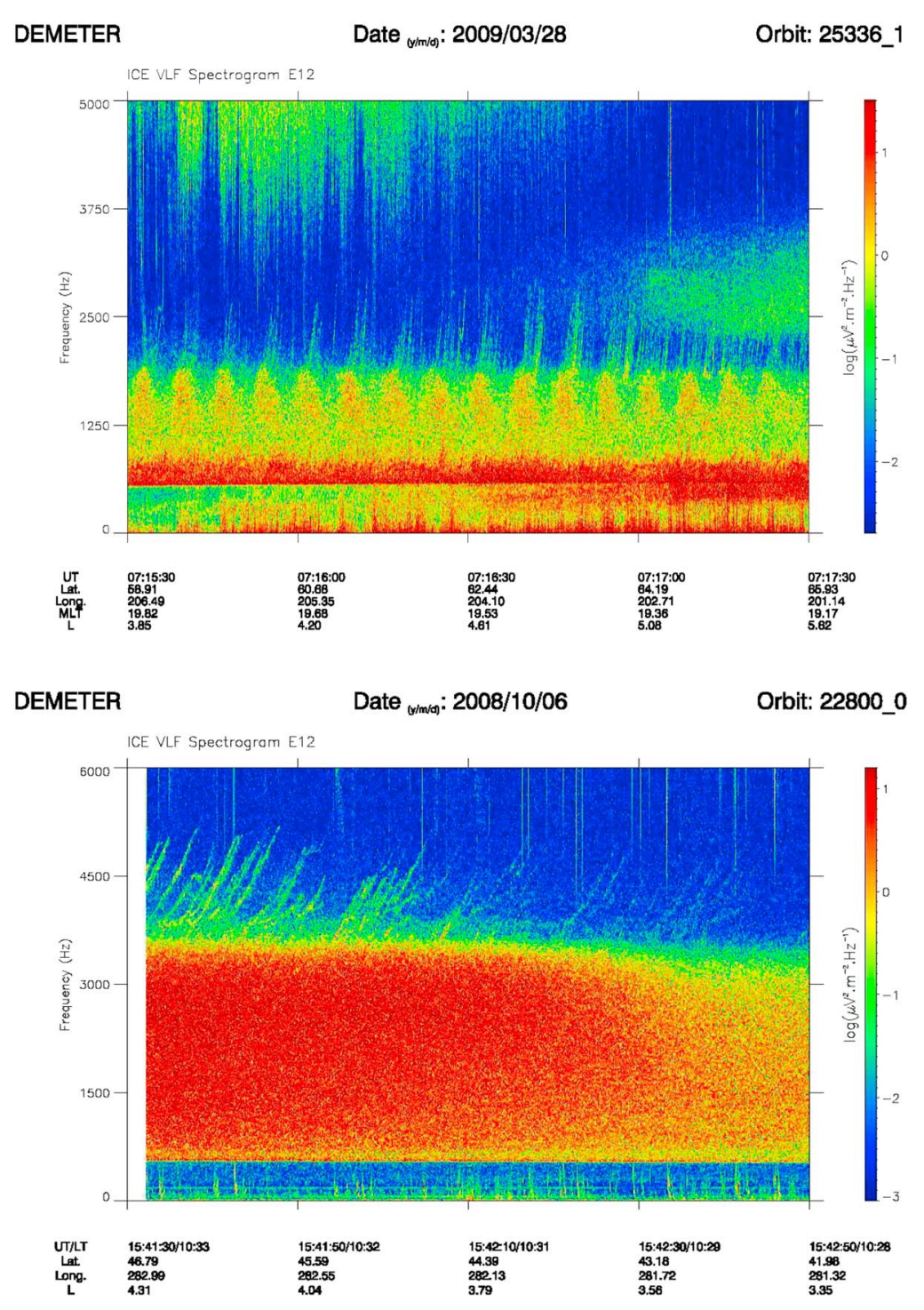

$\begin{array}{lll}\text { DEMETER } & \text { Date } \\ (y / \mathrm{m}(\mathrm{s}) & : 2006 / 10 / 30 & \text { Orbit: } 12412_{-} 1\end{array}$

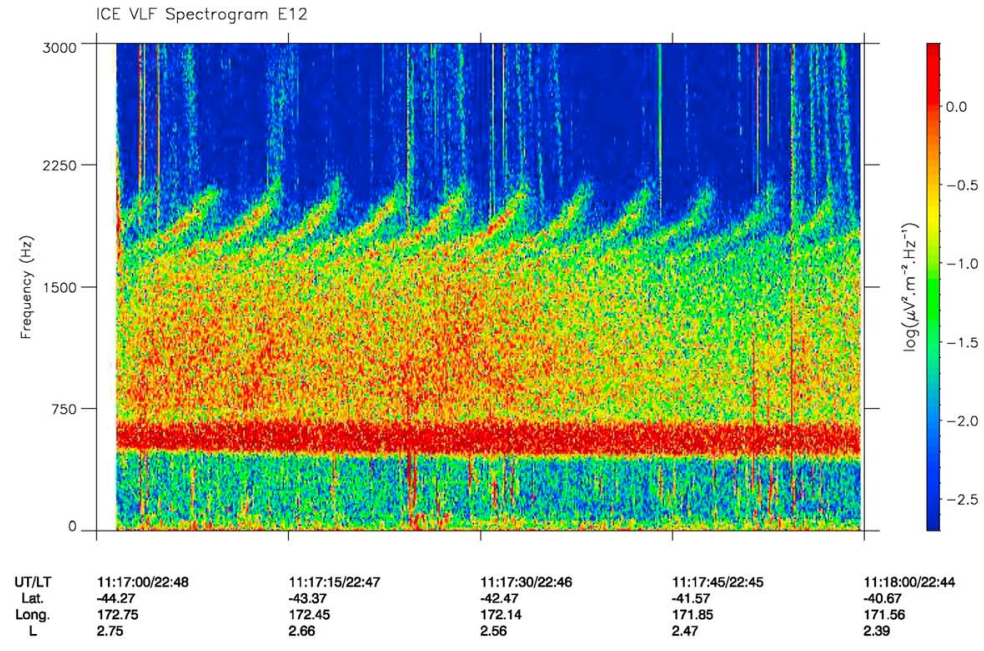

Figure 7 
propagating downward with low $\theta$ values $\left(20^{\circ}\right)$. The difference is that we can see below the proton gyrofrequency at the time of the ES turbulence that some elements are going upward which indicates that they suffer a reflection below the satellite. This might be consistent with reflection, near the $L=0$ cutoff frequency, of downgoing waves propagating nearly parallel to the Earth's magnetic field [Gurnett and Burns, 1968].

\subsection{Chorus-Like Emissions}

Most of the chorus observations are related to rising tones, but, for example, falling tones have been also observed onboard THEMIS (Time History of Events and Macroscale Interactions) [Li et al., 2011]. Onboard DEMETER, chorus with falling tones have not been recorded. But other emissions which can have certain similarities with chorus elements have been detected. In a spectrogram they always appear at the upper frequency limit of a nonstructured noise (hiss or large QP elements). A selection of events recorded by DEMETER is shown in Figure 7. Chorus-like elements emerging from QP emissions can be observed in Figure 7 (top) which displays a spectrogram up to $5 \mathrm{kHz}$ of an electric component registered on 28 March 2009 between 07:15:30 and 07:17:30 UT. At the beginning the intensity of these chorus-like elements is strengthened at the time of the QP elements, but it disappears at higher $L$ values. Filamentary structures emerging from a hiss band are displayed in Figure 7 (middle) which is related to a spectrogram up to $6 \mathrm{kHz}$ of an electric component registered on 6 October 2008 between 15:41:30 and 15:42:50 UT. Oppositely, Figure 7 (bottom) shows a spectrogram up to $3 \mathrm{kHz}$ of an electric component registered on 30 October 2006 between 11:17:00 and 11:18:00 UT with very thick elements also emerging from a hiss band. They look like QP emissions or bouncing elements with an average periodicity of $4.8 \mathrm{~s}$.

\section{Relations With PLHR}

In the two events shown in Figure 3 the upper bands are at usual frequencies at which PLHR are observed, i.e., in a frequency band from $1 \mathrm{kHz}$ to $3.5 \mathrm{kHz}$ with a peak around $2 \mathrm{kHz}$ [Němec et al., 2007]. The first event is recorded close to Alaska and the second one in the magnetic conjugate of Finland, two high-latitude regions where triggered emissions by PLHR are mostly recorded [see Parrot et al., 2014, Figure 5]. The frequency of the triggered elements observed in Figure 5 (around $2.5 \mathrm{kHz}$ ) also fit the frequencies of the PLHR. Figure 5 (top) is related to data recorded close to Alaska, i.e., in the hemisphere of PLHR emissions which must be emitted at harmonics of $60 \mathrm{~Hz}$, whereas Figure 5 (bottom) is related to data recorded in the opposite hemisphere conjugated to Alaska. It is not possible to visually observe PLHR on spectrograms because they must be present with a low intensity. But on ground it has been shown that PLHR lines correspond to the origin of the chorus-like elements [see Nunn et al., 1999, Figures 1-4].

\section{Conclusions}

A selection of ELF waves with sequences of elements with rising tones has been shown in this paper. It indicates that

1. The chorus elements in the lower frequency band always overlap with a hiss band which is limited by the proton gyrofrequency.

2. High-resolution spectrograms are necessary to identify discrete chorus-like elements and their origin.

3. The observed chorus emissions are emitted in the equatorial plane at high $L$ values and are propagating downward. Normally unducted whistler-mode waves suffer a magnetospheric reflection within the plasmasphere when the LHR (lower hybrid resonance) frequency is greater than the wave frequency. But, using ray tracing, it has been shown by Chum and Santolik [2005], Santolík et al. [2006], and Bortnik et al. [2008] that depending on the initial $\theta$ angles, waves emitted in the equatorial region can reach the ionosphere.

4. In addition, we observe that chorus propagation is guided by the plasmapause which is in agreement with past ray-tracing studies. Inan and Bell [1977] used a ray-tracing model to underline that the plasmapause

Figure 7. (top) Spectrogram up to $5 \mathrm{kHz}$ of an electric component registered on 28 March 2009 between 07:15:30 and 07:17:30 UT. (middle) Spectrogram up to $6 \mathrm{kHz}$ of an electric component registered on 6 October 2008 between 15:41:30 and 15:42:50 UT. (bottom) spectrogram up to $3 \mathrm{kHz}$ of an electric component registered on 30 October 2006 between 11:17:00 and 11:18:00 UT. 
can be considered as a guide for VLF waves. This guiding is comparable to that given by ducts and permits VLF waves which propagate near the inner edge of the plasmapause to be conducted down to the ionosphere, preventing reflection from the LHR layer. More recently, Golden et al. [2010], using also a ray-tracing code which included a plasmapause in the density model, have shown that waves emitted at the equator can reach the ground. Santolik et al. [2014] found that intense whistler-mode waves mostly propagate quasi-parallel to the magnetic field lines on their way from the source region.

5. When two frequency bands of chorus are simultaneously seen by DEMETER (Figure 5), these two chorus bands are not necessarily emitted around $\frac{1}{2} f_{\mathrm{ce}}$, but they most probably are coming from different equatorial locations.

6. PLHR can trigger elements which can be confused with chorus (Figure 5), even more if one frequency band of real chorus is present (Figure 3).

7. Filamentary elements emerging from a hiss band or from QP emissions (Figure 7) are not so structured as chorus emissions, although we believe they are emitted by a similar mechanism involving nonlinear wave-particle interactions.

Finally, this study could be considered as a follow-up of the work by Parrot et al. [2014] dealing with emissions triggered by PLHR which is the case for chorus-like elements.

\section{Acknowledgments}

This work is related to observations performed by the electric field instrument ICE and the magnetic field instrument IMSC aboard the satellite DEMETER which was launched by the Centre National d'Etudes Spatiales. The authors thank J.J. Berthelier the PI of ICE for the use of the data. The data presented in this paper are available at https://cdpp-archive.cnes.fr/. The work of F.N. was supported by GACR grant 15-01775Y. O.S. was supported by GACR grant 14-31899S, MSMT grant LH15304, and by the Praemium Academiae award.

\section{References}

Berthelier, J. J., et al. (2006), ICE, the electric field experiment on DEMETER, Planet. Space Sci., 54, 456-471, doi:10.1016/j.pss.2005.10.016.

Bortnik, J., R. M. Thorne, N. P. Meredith, and O. Santolik (2007), Ray tracing of penetrating chorus and its implications for the radiation belts, Geophys. Res. Lett., 34, L15109, doi:10.1029/2007GL030040.

Bortnik, J., R. M. Thorne, and N. P. Meredith (2008), The unexpected origin of plasmaspheric hiss from discrete chorus emissions, Nature, 452, 62-66.

Burtis, W. J., and R. A. Helliwell (1976), Magnetospheric chorus: Occurrence patterns and normalized frequency, Planet. Space Sci., 24, 1007-1010, doi:10.1016/0032-0633(76)90119-7.

Chen, L., J. Bortnik, W. Li, R. M. Thorne, and R. B. Horne (2012), Modeling the properties of plasmaspheric hiss: 1. Dependence on chorus wave emission, J. Geophys. Res., 117, A05201, doi:10.1029/2011JA017201.

Chum, J., and O. Santolik (2005), Propagation of whistler-mode chorus to low altitudes: Divergent ray trajectories and ground accessibility, Ann. Geophys., 23(12), 3727-3738.

Delport, B., A. B. Collier, J. Lichtenberger, C. J. Rodger, M. Parrot, M. A. Clilverd, and R. H. W. Friedel (2012), Simultaneous observation of chorus and hiss near the plasmapause, J. Geophys. Res., 117, A12218, doi:10.1029/2012JA017609.

Golden, D. I., M. Spasojevic, F. R. Foust, N. G. Lehtinen, N. P. Meredith, and U. S. Inan (2010), Role of the plasmapause in dictating the ground accessibility of ELF/VLF chorus, J. Geophys. Res., 115, A11211, doi:10.1029/2010JA015955.

Gurnett, D. A., and T. B. Burns (1968), The low-frequency cutoff of ELF emissions, J. Geophys. Res., 73(23), 7437-7445, doi:10.1029/ JA073i023p07437.

Inan, U. S., and T. F. Bell (1977), The plasmapause as a VLF wave guide, J. Geophys. Res., 82, 2819-2827, doi:10.1029/JA082i019p02819.

Kulkarni, V. H., and J. H. Das (1992), Very low frequency (VLF) chorus emissions: A topical survey, Surv. Geophys., 13(1), 35-46.

LeDocq, M., D. Gurnett, and G. Hospodarsky (1998), Chorus source locations from VLF Poynting flux measurements with the Polar spacecraft, Geophys. Res. Lett., 25, 4063-4066, doi:10.1029/1998GL900071.

Li, W., R. M. Thorne, J. Bortnik, Y. Y. Shprits, Y. Nishimura, V. Angelopoulos, C. Chaston, O. Le Contel, and J. W. Bonnell (2011), Typical properties of rising and falling tone chorus waves, Geophys. Res. Lett., 38, L14103, doi:10.1029/2011GL047925.

Luette, J. P., C. G. Park, and R. A. Helliwell (1977), Longitudinal variations of very-low-frequency chorus activity in the magnetosphere: Evidence of excitation by electrical power transmission lines, Geophys. Res. Lett., 4(7), 275-278, doi:10.1029/GL004i007p00275.

Manninen, J., N. G. Kleimenova, O. V. Kozyreva, M. Parrot, T. Raita, and T. Turunen (2012), Experimental evidence of the simultaneous occurrence of VLF chorus on the ground in the global azimuthal scale-From pre-midnight to the late morning, Ann. Geophys., 30, 725-732.

Němec, F., O. Santolik, M. Parrot, and J. J. Berthelier (2007), Comparison of magnetospheric line radiation and power line harmonic radiation: A systematic survey using the DEMETER spacecraft, J. Geophys. Res., 112, A04301, doi:10.1029/2006JA012134.

Nunn, D., J. Manninen, T. Turunen, V. Trakhtengerts, and N. Erokhin (1999), On the nonlinear triggering of VLF emissions by power line harmonic radiation, Ann. Geophys., 17, 79-94.

Omura, Y., and D. Nunn (2011), Triggering process of whistler mode chorus emissions in the magnetosphere, J. Geophys. Res., 116, A05205, doi:10.1029/2010JA016280.

Omura, Y., D. Nunn, H. Matsumoto, and M. J. Rycroft (1991), A review of observational, theoretical and numerical studies of VLF triggered emissions, J. Atmos. Terr. Phys., 53, 351.

Omura, Y., S. Nakamura, C. A. Kletzing, D. Summers, and M. Hikishima (2015), Nonlinear wave growth theory of coherent hiss emissions in the plasmasphere, J. Geophys. Res. Space Physics, 120, 7642-7657, doi:10.1002/2015JA021520.

Park, C. G., C. S. Lin, and G. K. Parks (1981), A ground-satellite study of wave-particle correlations, J. Geophys. Res., 86(A1), 37-53, doi:10.1029/ JA086iA01p00037.

Parrot, M., O. Santolík, N. Cornilleau-Wehrlin, M. Maksimovic, and C. Harvey (2003), Source location of chorus emissions observed by Cluster, Ann. Geophys., 21(2), 473-480.

Parrot, M., O. Santolík, N. Cornilleau-Wehrlin, M. Maksimovic, and C. Harvey (2004a), Magnetospherically reflected chorus waves revealed by ray tracing with Cluster data, Ann. Geophys., 21, 1111-1120.

Parrot, M., O. Santolík, D. Gurnett, J. Pickett, and N. Cornilleau-Wehrlin (2004b), Characteristics of magnetospherically reflected chorus waves observed by Cluster, Ann. Geophys., 22, 2597-2606.

Parrot, M., et al. (2006), The magnetic field experiment IMSC and its data processing onboard DEMETER: Scientific objectives, description and first results, Planet. Space Sci., 54, 441-455, doi:10.1016/j.pss.2005.10.015. 
Parrot, M., F. Nĕmec, and O. Santolík (2014), Statistical analysis of VLF radio emissions triggered by power line harmonic radiation and observed by the low-altitude satellite DEMETER, J. Geophys. Res. Space Physics, 119, 5744-5754, doi:10.1002/2014JA020139.

Santolik, O. (2008), New results of investigations of whistler-mode chorus emissions, Nonlinear Process. Geophys., 15(4), 621-630.

Santolík, O., and M. Parrot (1999), Case studies on wave propagation and polarization of ELF emissions observed by FREJA around local proton gyro-frequency, J. Geophys. Res., 104, 2459-2475, doi:10.1029/1998JA900045.

Santolík, O., F. Lefeuvre, M. Parrot, and J. L. Rauch (2001), Complete wave-vector directions of electromagnetic emissions: Application to INTERBALL-2 measurements in the nightside auroral zone, J. Geophys. Res., 106, 13,191-13,201, doi:10.1029/2000JA000275.

Santolik, O., J. S. Pickett, D. A. Gurnett, and L. R. O. Storey (2002), Magnetic component of narrow-band ion cyclotron waves in the auroral zone, J. Geophys. Res., 107(A12), 1444, doi:10.1029/2001JA000146.

Santolík, O., M. Parrot, and F. Lefeuvre (2003), Singular value decomposition methods for wave propagation analysis, Radio Sci., 38(1), 1010, doi:10.1029/2000RS002523.

Santolik, O., E. Macusova, K. H. Yearby, N. Cornilleau-Wehrlin, and H. S. C. K. Alleyne (2005), Radial variation of whistler-mode chorus: First results from the STAFF/DWP instrument onboard the Double Star TC 1 spacecraft, Ann. Geophys., 23, 2937-2942.

Santolik, O., J. Chum, M. Parrot, D. A. Gurnett, J. S. Pickett, and N. Cornilleau-Wehrlin (2006), Propagation of whistler mode chorus to low altitudes: Spacecraft observations of structured ELF hiss, J. Geophys. Res., 111, A10208, doi:10.1029/2005JA011462.

Santolík, O., F. Nĕmec, M. Parrot, D. Lagoutte, and L. Madrias (2006), Analysis methods for multi-component wave measurements on board the DEMETER spacecraft, Planet. Space Sci., 54, 512-527, doi:10.1016/j.pss.2005.10.020.

Santolík, O., E. Macúsová, I. Kolmasová, N. Cornilleau-Wehrlin, and Y. de Conchy (2014), Propagation of lower-band whistler-mode waves in the outer Van Allen belt: Systematic analysis of 11 years of multi-component data from the Cluster spacecraft, Geophys. Res. Lett., 41, 2729-2737, doi:10.1002/2014GL059815.

Sazhin, S. S., and M. Hayakawa (1992), Magnetospheric chorus emissions: A review, Planet. Space Sci., 40, 681-697, doi:10.1016/0032-0633(92) 90009-D.

Summers, D., Y. Omura, S. Nakamura, and C. A. Kletzing (2014), Fine structure of plasmaspheric hiss, J. Geophys. Res. Space Physics, 119, 9134-9149, doi:10.1002/2014JA020437.

Tsurutani, B. T., and Smith (1974), Postmidnight chorus: A substorm phenomenon, J. Geophys. Res., 79, 118-127, doi:10.1029/ JA079i001p00118.

Tsurutani, B. T., G. S. Lakhina, and O. P. Verkhoglyadova (2013), Energetic electron ( $>10 \mathrm{keV}$ ) microburst precipitation, $\sim 5-15 \mathrm{~s}$ X-ray pulsations, chorus, and wave-particle interactions: A review, J. Geophys. Res. Space Physics, 118, 2296-2312, doi:10.1002/jgra.50264.

Yizengaw, E., H. Wei, M. B. Moldwin, D. Galvan, L. Mandrake, A. Mannucci, and X. Pi (2005), The correlation between midlatitude trough and the plasmapause, Geophys. Res. Lett., 32, L10102, doi:10.1029/2005GL022954. 